\title{
Guest editorial: JACO going forward
}

\author{
Harry Blom ${ }^{1}$ (D)
}

Received: 2 February 2018 / Accepted: 2 February 2018 / Published online: 28 February 2018

C Springer Science+Business Media, LLC, part of Springer Nature 2018

It is our honor to welcome Dr. Ilias Kotsireas of Wilfrid Laurier University in Waterloo as the new Editor-in-Chief of the Journal of Algebraic Combinatorics (JACO). Dr. Kotsireas has already started to assemble a new and dynamic editorial board for JACO; his vision for JACO's next years is included in his Editorial following. We look forward to working with Dr. Kotsireas to ensure that JACO remains a strong forum at the forefront of academic research for many years to come.

Many of you may already be aware of the reasons for the recent change of editorial direction of JACO. In the summer of 2017, the editors-in-chief and editorial board of JACO informed Springer Nature of their decision to resign from the journal at the end of the year in order to set up a free access journal in algebraic combinatorics. Before their resignations were finalized, we engaged in discussions with these editors and proposed converting JACO into a fully open access journal. Unfortunately, the editors and Springer Nature had differing views about the best way to ensure the sustainability and longevity of this historic journal, and the editors left the board of JACO at the end of 2017.

As publishers and research collaborators, we believe that long-term economic sustainability and scientific neutrality are the basic prerequisites for disseminating scientific research, and maintaining and developing a healthy journal. However, we understand that the pace of change in the academic publishing industry in recent years could lead researchers, readership, and the general public to question what role the publishing industry has today. After all, digital technology allows anyone with an internet connection to post their research online at relatively little cost. From the viewpoint of working within a professional publishing company, we experience firsthand the extent of the complexities involved in running and maintaining a growing collection of publications. Indeed there is much more "behind the scenes" than is obvious.

\footnotetext{
$凶 \quad$ Harry Blom

harry.blom@springer.com

1 Springer Nature, 233 Spring St, New York, NY, USA
} 
In essence, we continually strive to serve our authors and readers in the best possible way. In this brief Editorial, we mention just a few examples of the way scientific publishers such as Springer Nature add value to the publishing process and advance the process of scientific discovery.

Established publishers like Springer Nature invest significantly in the development and maintenance of online platforms, where publications can be read, downloaded and disseminated. By virtue of such platforms, we can ensure a global readership for our content, which is further strengthened through numerous relationships with global distribution partners.

Through our paid partnerships with not-for-profit digital preservation organizations such as CLOCKSS and Portico, we strive to ensure the preservation of Springer Nature's online publications for future scholars, researchers and students.

Distribution of this content so that it reaches the maximum number of readers is also imperative, and much of our work goes into improving how articles are found, for instance, through optimizing article metadata tagging or innovative free services like Recommended which is a personalized service that recommends relevant papers based on what researchers have previously read from all publishers.

Each article published by Springer Nature goes through rigorous peer review. It is also copyedited and re-formatted to a uniform style which includes electronic internal and external links so that researchers can benefit from an enhanced reading and research experience. Dedicated marketing and communications departments develop and implement strategies to connect research with communities and the general public.

As members of COPE, Springer Nature is at the forefront of setting and maintaining the ethical standards for publishing compliance, and, in parallel, the expert handling of all legal matters including antipiracy, plagiarism claims, and rights registration.

These are just a few of the activities carried out by Springer Nature on a daily basis, and reflect the values that we are committed to continuing and improving.

The Archive of JACO has been open for free access and for personal use, for several years with papers over 36 month old hosted on the EMIS website. EMIS is still hosting all JACO papers published from 1992 through 2012, i.e., through Volume 36. To mark the journal's 25th anniversary, in 2017 Springer Nature provided a dedicated period of free access on SpringerLink to the entire archive of JACO. From 2018 onwards, the archive of the journal will be freely available for personal use for papers older than 30 months. These articles will be opened on a rolling basis on SpringerLink as well as on a mirror site now hosted by FIZ-Karlsruhe, eLibM. eLibM now hosts free accessibility to all JACO volumes through 41 . As with all journals published by Springer Nature, anyone with electronic access to JACO is also able to share any JACO article freely for web-browser reading through our SharedIt service.

We would like to thank all those who have played a role in the development of JACO in the past 25 years and look forward to working with many researchers to bring important work to the community in an established and reputable journal. Please let us know if there is anything that we can do to improve JACO in the months and years to come.

Harry Blom

Vice President Mathematics, Computer Science, and Publishing Development Springer Nature 